\title{
Nototanaids (Crustacea: Tanaidacea) from Japan, with the Description of a New Species of Nototanoides
}

\author{
Keiichi Kakui ${ }^{1,3}$ and Hiroshi Yamasaki ${ }^{2}$ \\ ${ }^{1}$ Department of Natural History Sciences, Faculty of Science, Hokkaido University, N10 W8, Sapporo 060-0810, Japan \\ E-mail:k_kakui@mail.goo.ne.jp \\ ${ }^{2}$ Faculty of Science, University of the Ryukyus, 1 Senbaru, Nishihara, Okinawa 903-0213, Japan \\ ${ }^{3}$ Corresponding author
}

(Received 10 July 2013; Accepted 30 October 2013)

\begin{abstract}
We describe a new nototanaid, Nototanoides ohtsukai sp. nov., based on specimens from the Yaku-Shin-Sone Bank, Nansei Archipelago, southern Japan (North Pacific Ocean). This species differs from its only congener, N. trifurcatus Sieg and Heard, 1985, in having a short distal article in the antennule and in the position of a row of aesthetascs on that article. We also present a partial redescription of the nototanaid Paranesotanais longicephalus Larsen and Shimomura, 2008 and a key to the genera of the families Nototanaidae and Tanaissuidae.
\end{abstract}

Key Words: Nototanaidae, Nototanoides, Paranesotanais, Tanaissuidae, new species, key, Japan.

\section{Introduction}

The family Nototanaidae consists of seven genera and eleven species (Anderson 2013). Except for the species of Stachyops and Nototanais, nototanaids have generally been reported from tropical and subtropical regions (Fig. 1A; Sieg 1980, 1986; Sieg and Heard 1985; Larsen 2005; Larsen and Shimomura 2008; Kakui et al. 2010; Araújo-Silva and Larsen 2012; Bamber 2012; Bird 2012b; Esquete et al. 2012; Kakui and Angsupanich 2012; this study). Two nototanaids are known from Japan. One is Nesotanais ryukyuensis Kakui, Kajihara and Mawatari, 2010, which was described from a brackish habitat on Okinawa Island and which has also been collected from Iriomote and Amami-Oshima Islands (Fig. 1B; Kakui et al. 2010; Kakui unpubl. data). The other is Paranesotanais longicephalus Larsen and Shimomura, 2008 (the only species in its genus), which was described from a shallow subtidal bottom around Aka Island, Kerama Islands (Fig. 1B; see Larsen and Shimomura 2008).

In 2008 and 2011 we collected specimens of a nototanaid species from depths of $155-201 \mathrm{~m}$ on the Yaku-Shin-Sone Bank, Nansei Archipelago, southern Japan. This proved to be an undescribed species of Nototanoides, and we describe it here. In addition, we provide a partial redescription of $P$. longicephalus to confirm several character states that were unclear in the original description. Finally, we present a key to the genera of the closely related families Nototanaidae

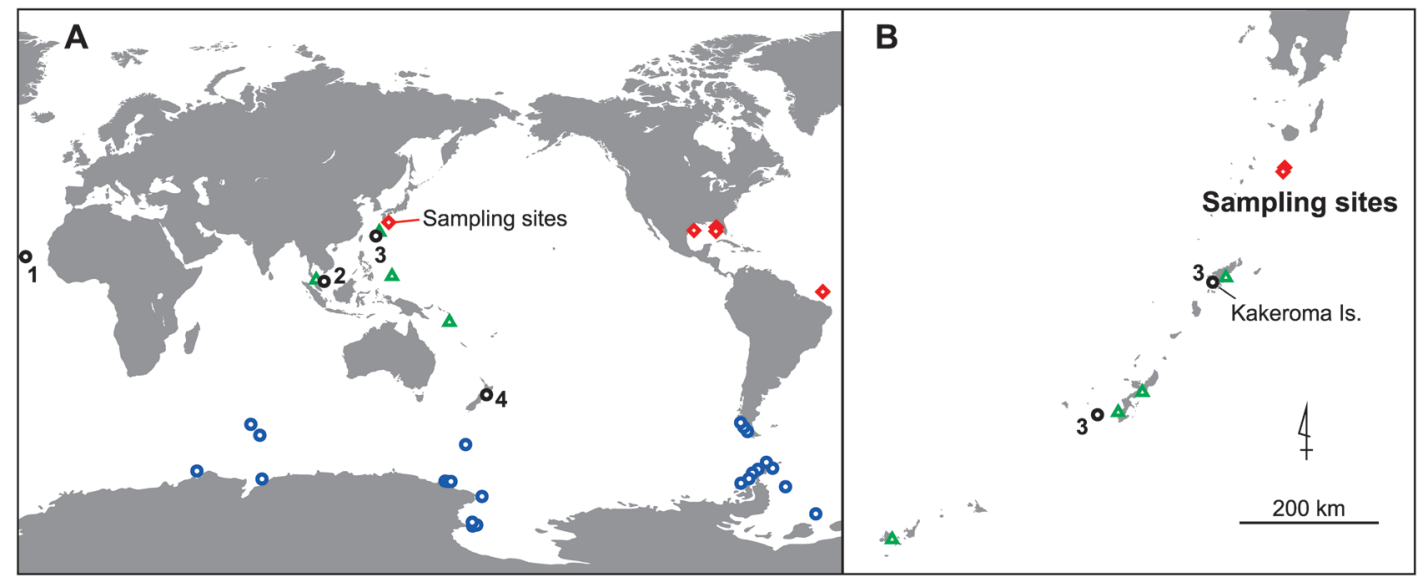

Fig. 1. Maps showing nototanaid distributions. A, global distribution of nototanaids, including the sampling sites for Nototanoides ohtsukai sp. nov.; B, nototanaid records in Japan, with the sampling sites for Nototanoides ohtsukai sp. nov. Symbols: red diamonds, Nototanoides; green triangles, Nesotanais; blue circles, Nototanais; black circles (1-4), Gamboa, Birdotanais, Paranesotanais, and Stachyops, respectively. 
and Tanaissuidae.

\section{Materials and Methods}

Specimens of Nototanoides were collected by using a biological dredge during cruises of the R/V Soyo-maru (National Research Institute of Fishery Science) and TR/V Toyoshio-maru (Hiroshima University); specimens of Paranesotanais were collected by scuba from a shallow subtidal bottom around Kakeroma Island, Amami Islands (Fig. $1 \mathrm{~B})$. The material examined in this study is deposited in the Zoological Institute, Faculty of Science, Hokkaido University, Sapporo, Japan (ZIHU), and the National Museum of Nature and Science, Tsukuba, Japan (NSMT). Methods for dissecting, preparing, observing, and drawing specimens were as described in Kakui and Angsupanich (2012). Terminology relevant to orientation and morphology follows the usage of Larsen (2003), except that the term "plumose sensory seta" (Bird 2011) is used here instead of "broom seta". Body length (BL) was measured from the tip of the eye lobe to the tip of the pleotelson; body width was measured at the widest portion of the cephalothorax (i.e., cephalothorax width; CW). Measurements were made axially: dorsally on the body, antennules, antennae, pleopods, and uropods; laterally on the pereopods. All measurements in the text are in millimetres unless noted otherwise. The terms "preparatory" (Prep), "ovigerous" (Ovi), and "post-ovigerous" (PO) for females follow the usage of Bird (2011).

\section{Family Nototanaidae Sieg, 1976}

Diagnosis [after Bird and Larsen (2009)]. Eyes present. Pereonites 1-3 not reduced. Female antennule with three articles. Male mouthparts reduced. Female mandibular incisors facing inward; right incisor with subdistal crenulation. Female mandibular molars broad, with heavily chitinised grinding surface. Cheliped attachment via triangular sclerite. Female chelipedal dactylus without dorsal crenation/nodules. Pereopods 4-6 lacking coxae and clinging apparatus. Uropodal endopod with two articles.

\section{Genus Nototanoides Sieg and Heard, 1985 Nototanoides ohtsukai sp. nov.}

(Figs 2-5)

Material examined. Holotype. Ovi female, ZIHU-4401; BL 2.75, CW 0.45; five slides and one vial; R/V Soyo-maru, Yaku-Shin-Sone Bank, North Pacific Ocean, $29^{\circ} 47.0^{\prime} \mathrm{N}$, $130^{\circ} 22.6^{\prime} \mathrm{E}$ to $29^{\circ} 47.6^{\prime} \mathrm{N}, 130^{\circ} 23.0^{\prime} \mathrm{E}, 155-175 \mathrm{~m}$ depth, biological dredge, 2 August 2008, collected by Ken Fujimoto and Takami Morita (sorted by Hironori Komatsu).

Allotype. Male, ZIHU-4402; BL 2.46, CW 0.39; three slides and one vial; same collection data as for holotype.

Paratypes. PO female, ZIHU-4403; BL 2.70, CW 0.36; four slides and one vial. Ovi female, ZIHU-4404; BL 2.66, CW 0.43; four slides and one vial. Ovi female, ZIHU-4405; BL 2.63, CW 0.36; one slide and one vial. Female, ZIHU-
4408; BL 1.58, CW 0.23; one vial. Female, ZIHU-4409; BL 2.46, CW 0.30; one vial. Male, ZIHU-4406; BL 2.54, CW 0.37; four slides and one vial. Male, ZIHU-4407; BL 2.11, CW 0.27; one slide and one vial. Four individuals, ZIHU4410; all intact, one vial. Four individuals, NSMT-Cr 22361; all intact, one vial. ZIHU-4403-4406, ZIHU-4410, and NSMT-Cr 22361, same collection data as for holotype; ZIHU-4407-4409, TR/V Toyoshio-maru, Yaku-ShinSone Bank, North Pacific Ocean, $29^{\circ} 49.26^{\prime} \mathrm{N}, 130^{\circ} 24.55^{\prime} \mathrm{E}$ to $29^{\circ} 48.75^{\prime} \mathrm{N}, 130^{\circ} 24.45^{\prime} \mathrm{E}, 201-198 \mathrm{~m}$ depth, biological dredge, 18 May 2011, collected by Susumu Ohtsuka and Hiroshi Yamasaki.

Diagnosis. Relative length of distal article to article 2 in antennule $0.42-0.49$ in females, $0.38-0.39$ in males. Row of aesthetascs on distal article of antennule located on midventral region.

Description of female. Based primarily on holotype, with some observations from paratypes ZIHU-4403-4405. Body (Fig. 2A, C) dorsoventrally flattened, 6.11 times as long as wide. Cephalothorax 0.24 times $\mathrm{BL}$, with one pair of lateral simple setae posterior to eyes; rostrum blunttriangular; dorsal region of carapace smooth. Pereonites each with one pair of dorsolateral simple setae; pereonites 4-6 each with one pair of lateral simple setae. Pleon 0.27 times BL. Pleonites as wide as pereon; all similar in shape, each with one pair of dorsolateral simple setae and row of lateral simple setae. Pleotelson slightly narrower than pleonites, wider than long, trapezoidal, with one pair each of lateral, posteriolateral, and posterior simple setae.

Antennule (Fig. 3A, a1) 0.72 times cephalothorax length; length ratio of articles 1-3 3.52:1.00:0.49. Article 1 with two outer and two inner simple setae and several plumose sensory setae. Article 2 with two simple setae and one plumose sensory seta. Article 3 with six distal simple setae, one distal plumose sensory seta, and one distal and four mid-ventral aesthetascs. Antenna (Fig. 3B) with six articles; length 0.82 times antennule length; length ratio of articles 1-6 1.00:2.16:0.81:3.98:0.52:0.11. Article 1 naked. Articles 2 and 3 each with one dorsodistal setulate seta. Article 4 with one simple seta and several plumose sensory setae. Article 5 with one simple seta. Article 6 with five simple setae.

Labrum (ZIHU-4405; Fig. 3C) rounded; distal region setulate; distolateral region with several teeth. Mandibles (Fig. $3 \mathrm{D}, \mathrm{E})$ with broad masticatory region bearing several teeth. Left mandible (Fig. 3D) with several teeth on incisor and five teeth on lacinia mobilis; right mandible (Fig. 3E) with bifurcate incisor. Labium (Fig. 3F) with inner lobe bearing tiny ventrolateral spine; outer lobe well developed, rounded, with outer serration. Maxillule (ZIHU-4404; Fig. 3G) with outer clumps of short setae; endite with nine spiniform setae. Maxillular palp with two setae at tip. Maxilla (ZIHU4404; Fig. 3G) subovate, naked. Maxillipeds (Fig. 3H, h1, h2, I) with bases fused, bearing one ventral simple seta (reaching beyond distal margin of endite) at insertion of palp. Endites distally separated; outer margin setulate; each distal margin with one shorter (shorter than 0.33 times longer simple seta length) and one longer simple setae, and two flat tubercles or "membranous hemispherical structures" (Sieg 

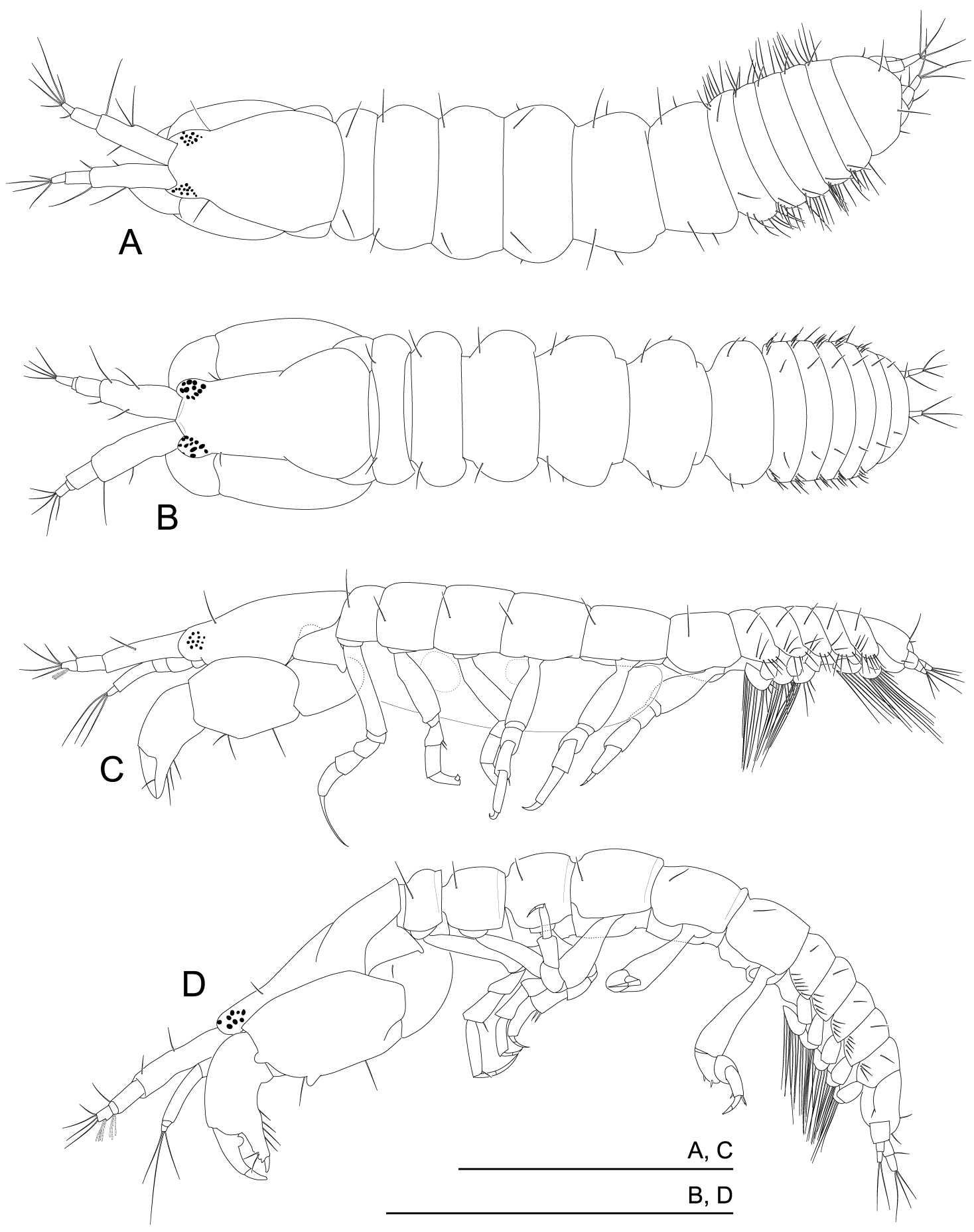

Fig. 2. Nototanoides ohtsukai sp. nov. A, C, holotype, female; B, D, allotype. A, B, body, dorsal view; C, D, body, lateral view. Scale bars: $1 \mathrm{~mm}$.

and Heard 1985); flat tubercles large, partly overlapping (Fig. 3h1). Maxillipedal palp (Fig. 3h2) with article 1 naked; article 2 with two inner simple setae and one multifurcate spiniform seta; article 3 with one simple seta and three thick bipinnate setae in inner region; article 4 with one subdistal simple seta and five inner thick bipinnate setae. Epignath (ZIHU-4405; Fig. 3J) narrow, curved, with one distal circumplumose seta.

Cheliped (Fig. 4A, a1, a2) with basis slightly longer than wide, bearing small free posterior portion and one outer simple seta. Merus triangular, with one ventral simple seta. Carpus 1.6 times as long as wide, with one dorsoproximal, one dorsodistal, and two ventral simple setae. Chela with four ventral simple setae. Propodal palm with one outer and one inner simple setae, and inner row of minute setae at insertion of dactylus. Fixed finger with claw; cutting surface with two middle simple setae, one middle sinuate spiniform seta (Fig. 4a1), and one outer distal rectangular lamellar projection. Dactylus 1.5 times as long as fixed finger, with one inner proximal bipinnate seta; cutting surface with one 


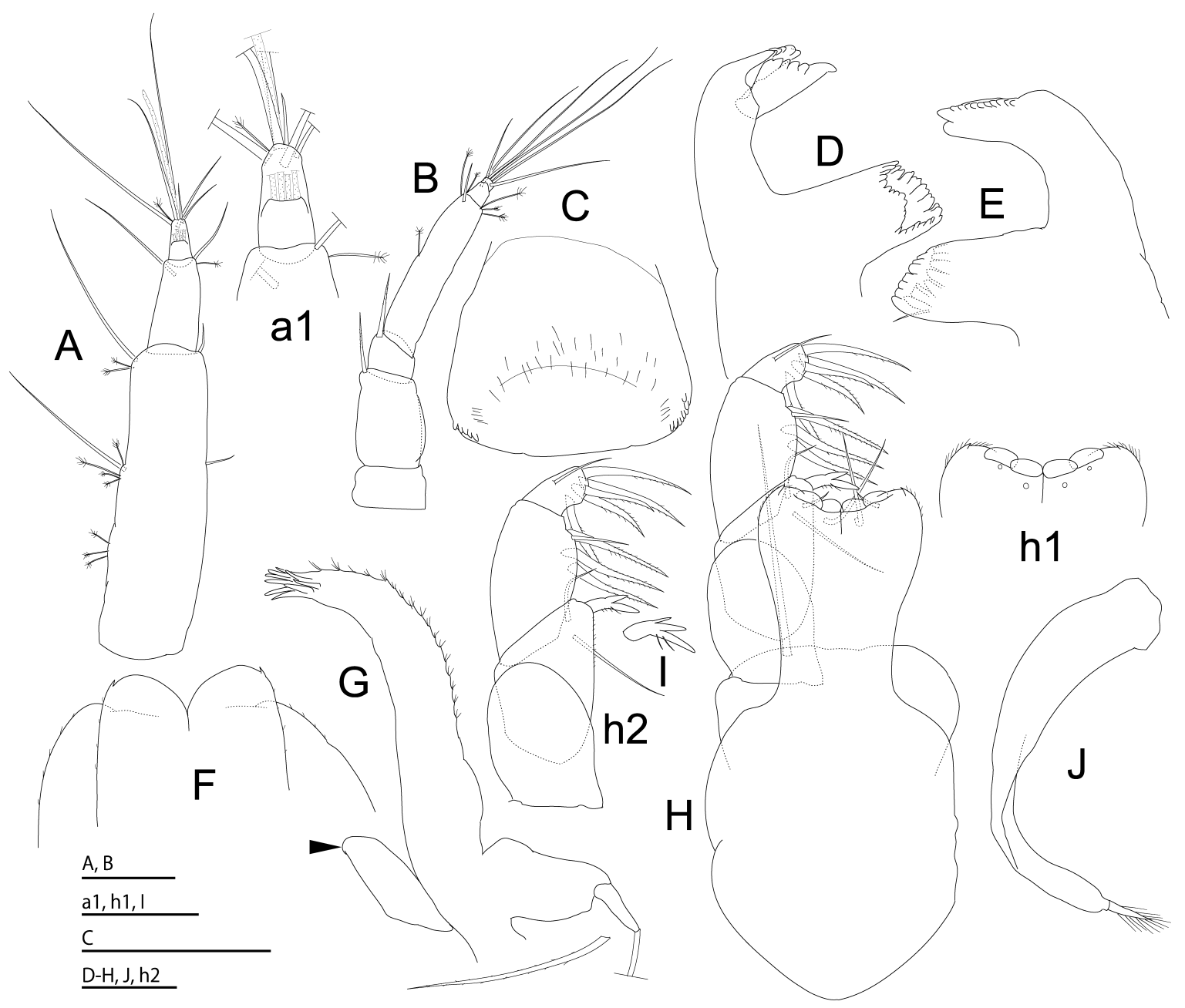

Fig. 3. Nototanoides ohtsukai sp. nov., female. A, B, D-F, H, holotype; C, J, paratype (ZIHU-4405); G, I, paratype (ZIHU-4404). A, right antennule, ventral view; a1, same, distal portion; B, right antenna, outer view; C, labrum, anterior view; D, left mandible, anterior view; E, right mandible, anterior view; F, labium; G, right maxillule and maxilla (arrowhead); $H$, maxillipeds, dorsal view (right palp removed); h1, same, distal region of endite, ventral view; h2, same, left palp; I, multifurcate spiniform seta (in trifurcate case); J, right epignath. Scale bars: A, B, $0.1 \mathrm{~mm}$; C-J, h1, h2, $0.05 \mathrm{~mm}$.

small mid-ventral process (not illustrated) and several teeth.

Pereopods 1-6 with length ratio of $1.55: 1.00: 1.01: 1.07$ : 1.14:1.18. Pereopod 1 (Fig. 4B) 0.36 times BL. Coxa with one simple seta. Length ratio of basis, ischium, merus, carpus, propodus, and dactylus-unguis $3.38: 0.21: 1.00: 1.07$ : $1.66: 1.76$. Basis cylindrical, narrow (6.0 times as long as wide), with one dorsal simple seta and one dorsal plumose sensory seta. Ischium and merus each with one ventral simple seta; merus obliquely articulated with carpus. Carpus with four distal simple setae. Propodus with one dorsal and one ventral simple setae, and dorsodistal setulation. Dactylus with one simple seta. Unguis twice as long as dactylus. Pereopod 2 (ZIHU-4403; Fig. 4C) with length ratio of basis, ischium, merus, carpus, propodus, and dactylus-unguis $3.28: 0.20: 1.00: 1.28: 1.41: 0.94$. Coxa, basis, and ischium like those of pereopod 1, except basis shorter. Merus with one ventral simple seta and one ventral spiniform seta. Carpus with four distal spiniform setae. Propodus with one ventral spiniform seta and dorsodistal setulation. Dactylus naked. Unguis 1.9 times as long as dactylus. Pereopod 3 (Fig. 4D) similar to pereopod 2, except basis with one additional plumose sensory seta, and carpus with only three distal spiniform setae. Pereopod 4 (Fig. 4E, e1) with length ratio of basis, ischium, merus, carpus, propodus, and dactylus-unguis $3.13: 0.21: 1.00: 1.16: 1.69: 0.93$. Basis thick (2.6 times as long as wide), with two dorsoproximal and two ventrodistal plumose sensory setae. Ischium with two ventral simple setae. Merus with two ventrodistal spiniform setae. Carpus with one dorsodistal simple seta and three distal spiniform setae. Propodus with one mid-dorsal plumose sensory seta, one dorsodistal pinnate seta (Fig. $4 \mathrm{e} 1$ ), two ventrodistal spiniform setae, and dorsodistal setulation. Dactylus-unguis curved ventrally, with thick basal part bearing dorsoproximal setulation. Unguis 0.70 times as long as dactylus. Pereopod 5 (Fig. 4F) similar to pereopod 4, except ischium bearing one additional simple seta, and carpus with four distal spiniform setae. Pereopod 6 (Fig. $4 \mathrm{G}, \mathrm{g} 1$ ) similar to pereopod 4 , except basis bearing only one dorsoproximal plumose sensory seta, carpus with four distal spiniform setae, and propodus with two dorsodistal serrate setae (Fig. 4g1).

Pleopods (Fig. $4 \mathrm{H}$ ) all similar. Basal article naked. Endo- 


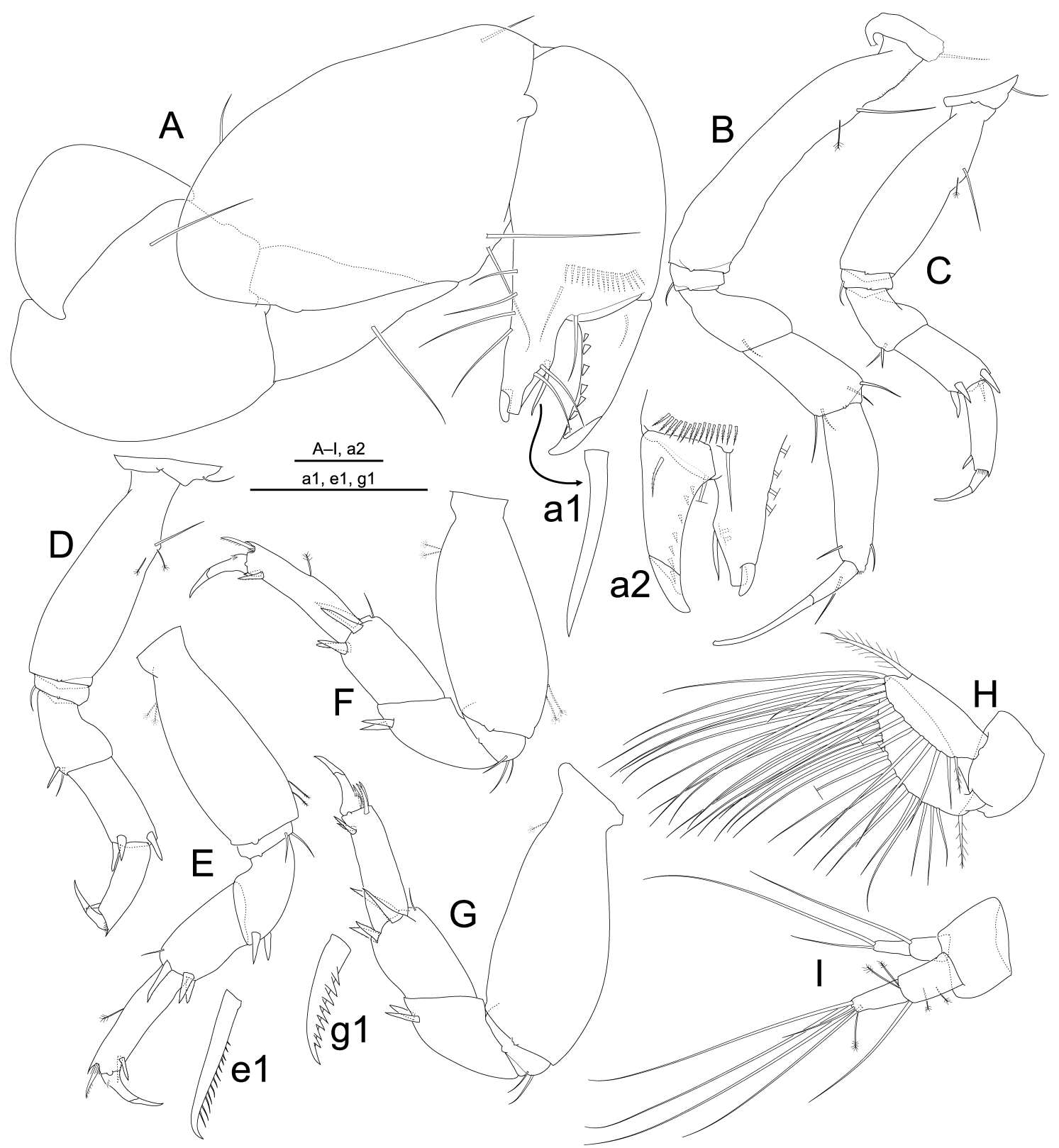

Fig. 4. Nototanoides ohtsukai sp. nov., female. A, B, D-I, holotype; C, paratype (ZIHU-4403). A, right cheliped, outer view (outer ventral view for chela); a1, same, sinuate spiniform seta; a2, same, inner dorsal view of chela; B-G, right pereopods 1-6, outer view; e1, pinnate seta; g1, serrate seta; H, right pleopod 1, dorsal view, most setal ornamentation omitted; I, right uropod, ventral view. Scale bars: A-I, a2, $0.1 \mathrm{~mm}$; al, el, g1, $0.05 \mathrm{~mm}$.

pod with 10-12 plumose setae and one distal "step-tipped plumose seta" (see Kakui et al. 2010: fig. 5j2) on outer margin, and one inner subdistal step-tipped plumose seta. Exopod longer than endopod, with 23-25 outer plumose setae; "outer process" (Larsen and Froufe 2013) [="vestigial proximal article" (Bird 2012a)], with one outer plumose seta.

Uropod (Fig. 4I) with basal article naked. Endopod article 1 with one simple seta and four plumose sensory setae; article 2 with five simple setae and one plumose sensory seta. Exopod article 1 with one simple seta; article 2 slightly shorter than article 1, with two simple setae.

Description of male. Based on allotype. Body (Fig. 2B, D) 6.30 times as long as wide. Otherwise similar to females, except cephalothorax more slender in anterior half, all pe- reonite articulations more constricted than those of female, and pereonite 6 with pair of genital cones.

Antennule (Fig. 5A, a1) with four articles, 0.73 times cephalothorax length; length ratio of articles 1-4 3.45: 1.00:0.16:0.38. Articles 1 and 2 similar to those of female. Article 3 with three ventrodistal aesthetascs. Article 4 with six distal simple setae, one plumose sensory seta, and one distal and four mid-ventral aesthetascs. Antenna (Fig. 5B) 0.82 times antennule length, with six articles; length ratio of articles 1-6 1.00:2.39:0.86:4.76:0.69:0.18. Articles 1, 2, 4, and 5 similar to those of female. Article 3 with exoskeleton thickened in part of distal half (Fig. 5B: arrowhead), bearing one dorsodistal setulate seta. Article 6 with six simple setae.

Labrum (Fig. 5C) naked. Maxillule (Fig. 5D) with naked 


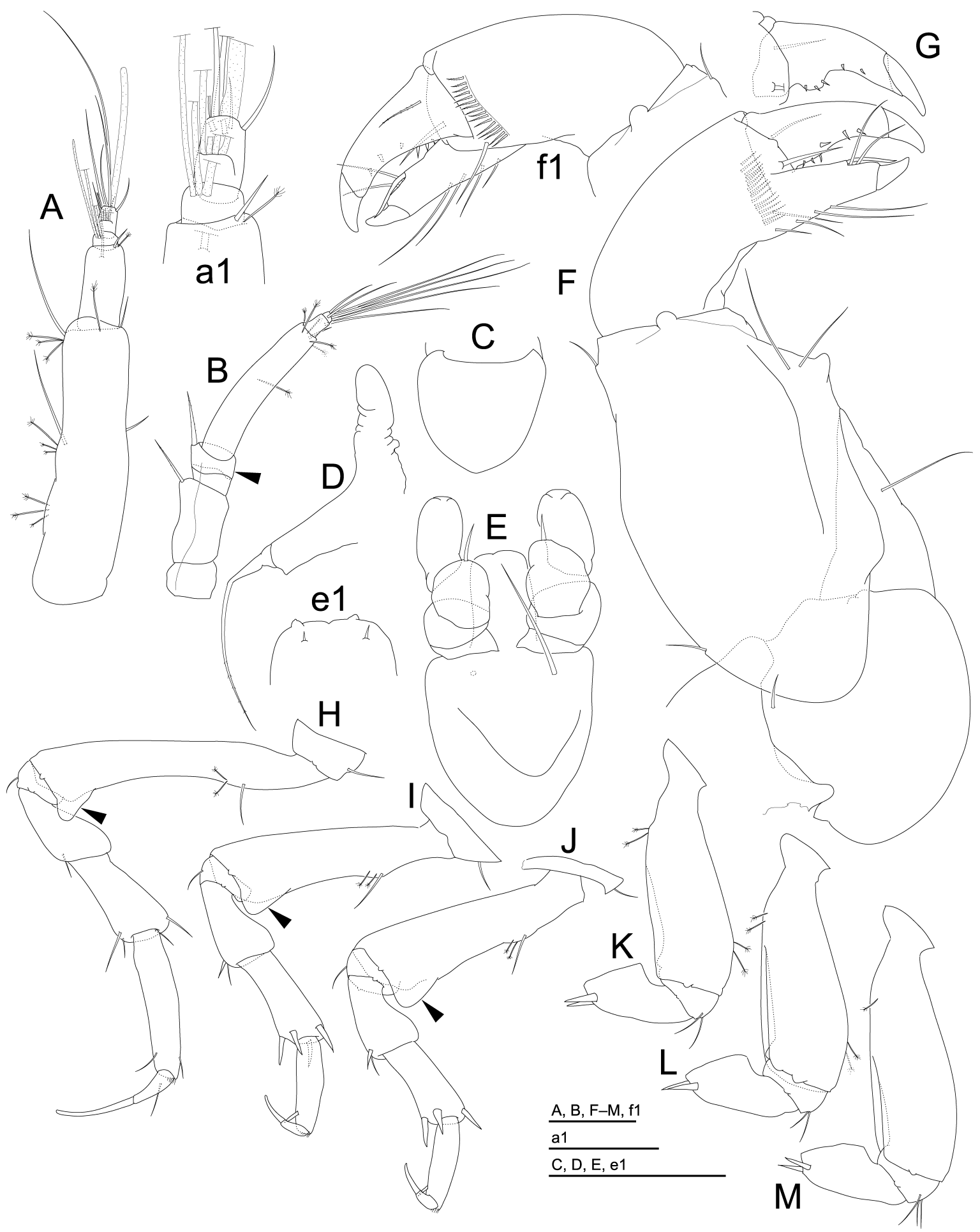

Fig. 5. Nototanoides ohtsukai sp. nov., male. A-F, H-J, allotype; G, paratype (ZIHU-4406). A, right antennule, ventral view; a1, same, distal portion; B, right antenna with region of thickened exoskeleton in article 3 (arrowhead), outer view; C, labrum, D, right maxillule; E, maxillipeds, ventral view; e1, same, distal region of endite, ventral view; F, right cheliped, outer view (outer ventral view for chela); f1, same, chela, inner dorsal view; G, right cheliped dactylus, outer view. H-J, right pereopods 1-3 with outer dorsodistal lamellar projection (arrowheads), outer view; K-M, right pereopods 4-6 (basis, ischium, and merus only), outer view. Scale bars: A-M, f1, 0.1 mm; a1, e1, $0.05 \mathrm{~mm}$.

endite; palp with one seta. Maxillipeds (Fig. 5E, e1) with bases completely fused, bearing one ventral simple seta at insertion of palp. Endites completely fused medially but distal margin slightly concave, each with one ventral small simple seta and one small process. Palp with four articles; article
3 with one distal simple seta.

Cheliped (Fig. 5F, f1) with basis and merus similar to those of female. Carpus 1.75 times as long as wide, with one dorsoproximal, one dorsodistal, and two ventral simple setae, and one ventral process. Chela otherwise similar to 
that of female, except fixed finger lacking distal rectangular lamellar projection, and process on dactylus larger than that of female.

Pereopods 1-3 (Fig. 5H-J) similar to those of female, except basis bearing outer dorsodistal lamellar projection (Fig. 5H-J: arrowheads). Pereopods 4-6 (Fig. 5K-M), pleopods, and uropod generally similar to those of female.

Variation. The length of the antennule's distal article relative to article 2 varies: in females, $0.49,0.43$, or 0.42 (ZIHU-4401, 4403, 4404, respectively); in males, 0.38, 0.39, or 0.39 (ZIHU-4402, 4406, 4407, respectively). The distal article of antennule bears five simple setae in three paratypes (ZIHU-4404, 4406, 4407). The number of aesthetascs in the mid-ventral region of the antennule's distal article varies: two (in ZIHU-4407), three (in ZIHU-4403, 4406), or four (ZIHU-4401, 4402, 4405). Antennal article 6 has four (ZIHU-4404), five (ZIHU-4401, 4403, 4406), or six (allotype) simple setae. The shape of the multifurcate seta on article 2 of the maxillipedal palp varies in females: bifurcate in two individuals (ZIHU-4401, 4405; Fig. 3h2); trifurcate in two individuals (ZIHU-4403, 4404; Fig. 3I). The number of simple setae on article 2 of the maxillipedal palp varies in males: one in two individuals (ZIHU-4402, 4407); two in ZIHU-4406. The number of ventral simple setae on the chela is three in two paratypes, ZIHU-4403 and 4407. The carpus of pereopod 3 has four distal spiniform setae in one female (ZIHU-4403). Three ventral simple setae are present on the pereopod 5 ischium of two specimens (ZIHU-4401 and 4403), and on the ischium of pereopod 6 ischium of the allotype. Article 2 of the uropodal endopod bears four simple setae in ZIHU-4404, but two plumose sensory setae in ZIHU-4403. Two plumose sensory setae are present in the dorsoproximal region on the basis of pereopod 2 in ZIHU4402 and 4404.

The carpus of pereopod 4 has four distal spiniform setae, except in the holotype; four may thus be the usual condition.

In addition to the antennule, mouthparts, and chelipeds, marked sexual dimorphism is evident in the bases of pereopods 1-3, which bear an outer dorsodistal lamellar projection in males.

Etymology. The specific name honours Susumu Ohtsuka, organizer of serial benthos/plankton surveys in southwestern Japan by the TR/V Toyoshio-maru, which procured many tanaidaceans.

Remarks. Nototanoides ohtsukai sp. nov. is the second species described in this genus. The type species, N. trifurcatus Sieg and Heard, 1985, was originally described from the Gulf of Mexico; Araújo-Silva and Larsen (2012) subsequently reported $N$. cf. trifurcatus from the North Chain Banks, Brazil, adding brief remarks. Nototanoides ohtsukai can be distinguished from $N$. trifurcatus by the length of the distal article (article 3 for females; article 4 for males) of the antennule and the position of the row of aesthetascs on this article (character states of $N$. trifurcatus are in parentheses): relative length of distal article to article 2 $0.42-0.49$ in females [0.66; measured from fig. 2 in Sieg and Heard (1985)], 0.38-0.39 in males [0.57 for "male Type 1", 0.63 for "male Type 2"; measured from fig. 2 in Sieg and Heard (1985)]; two to four aesthetascs in mid-ventral region (four in ventroproximal region). Note that Sieg and Heard (1985: p. 60) described that "second segment smaller, about 2 times longer than broad, sternal margin distally with 4 aesthetascs" for the female antennule; based on their fig. 2 and the condition in female N. ohtsukai, however, the four aesthetascs appear to be in the proximal region of article 3, or on the "vestigial segment" as Bird (2012a) suggested. In addition to the previous two characters, the chela of $N$. ohtsukai bears one sinuate spiniform seta, which is lacking in N. trifurcatus.

Females of N. ohtsukai differ from those of N. trifurcatus in some maxillipedal features. The former have endites with a short simple seta and the large, overlapping flat tubercles; the latter have a medium-long simple seta [longer than half the length of the longer simple seta; measured from Sieg and Heard (1985: fig. 3)] and an apparent gap between the two flat tubercles. The number of ventral simple setae on the chela also differs between the two species (three or four in N. ohtsukai; six in N. trifurcatus).

Males of N. ohtsukai have maxillipeds that are not strongly reduced and bear endites and palps with four articles. In contrast, males of $N$. trifurcatus have strongly reduced maxillipeds lacking palps. The fixed finger of the chela in males of $N$. ohtsukai bears a triangular claw, instead of the reduced, rounded tooth of $N$. trifurcatus. Sieg and Heard (1985) illustrated outer and inner broad lamellar projections on the bases of pereopods 1-6 of male N. trifurcatus, with those on the pereopods 4-6 being strongly developed. Males of N. ohtsukai bear similar structures, but only the outer one is well developed (triangular) on pereopods $1-3$ (Fig. 5H-J: arrowheads) whereas those on the pereopods $4-6$ are not well developed.

Sieg and Heard (1985) recognized two male morphs, large "male Type 1" and small "male Type 2", in male N. trifurcatus, which differ in body size and the shape of the cheliped. Diandry (cf. Sadovy and Domeier 2005) has been demonstrated (Bückle Ramírez 1965) or strongly indicated (Gardiner 1975) in some tanaidomorphs such as Heterotanais oerstedii (Krøyer, 1842) and Neotanais micromopher Gardiner, 1975. Bückle Ramírez (1965) showed that, in addition to primary males ("Primärmännchen"), three other types of males ("Sekundärmännchen", or secondary males) that differ in body size, cheliped shape, and cephalothorax shape, arise by sex change from females in different developmental stages (see his table 10 and fig. 42). Based on this knowledge, Sieg and Heard (1985) suggested that the two types of male in $N$. trifurcatus might likewise result from that species' diandric reproductive mode. We found large (ZIHU4402, 4406) and small (ZIHU-4407) males in N. ohtsukai, which might similarly indicate diandry, but more data such as from breeding experiments are necessary to confirm this interpretation.

Distribution. So far, this species is known only from the type locality. 
Genus Paranesotanais Larsen and Shimomura, 2008

Paranesotanais longicephalus Larsen and Shimomura, 2008

(Fig. 6)

Paranesotanais longicephalus Larsen and Shimomura, 2008, $10-22$.

Paranesotanais malignus: Bird 2012a, table 1.

Material examined. One female, ZIHU-4411; BL 2.29, CW 0.30; one slide and one vial; $28^{\circ} 11^{\prime} 14^{\prime \prime} \mathrm{N}, 129^{\circ} 14^{\prime} 34^{\prime \prime} \mathrm{E}$ (retrieved from Google Earth), Kakeroma Island, Amami Islands, 1-4 m, coral sand, 28 June 2006, collected by Tadashi Akiyama. One male, ZIHU-4412; BL 2.80, CW 0.28; two slides and one vial; same collection data as for ZIHU-4411.

Partial redescription of both sexes. Rostrum bilobed (Fig. 6A). Each pleonite with two pairs (one pair on pleonite 5) of lateral simple setae; pleonites 1 and 5 with one pair of dorsolateral simple seta (Fig. 6B).

Female antennule (Fig. 6C) with three articles; length ratio of articles 1-3 5.20:1.00:1.45. Article 1 with two outer and two inner simple setae, and several plumose sensory setae. Article 2 with two simple setae and one plumose sensory seta. Article 3 with six distal simple setae, one distal plumose sensory seta, and one distal and three proximal aesthetascs.

Male antennule (Fig. 6D) with four articles; length ratio of articles 1-4 8.16:1.20:1.00:1.18. Articles 1 and 2 similar to those of female. Article 3 with three distal aesthetascs. Article 4 similar to that of female except lacking proximal aesthetascs.

Male maxillular palp (Fig. 6E) with four setae. Male maxillipeds (Fig. 6F) firmly connected with exoskeleton of cephalothorax. Bases fused medially, with one pair of simple setae. Endites absent. Palp with four articles; article 4 with one bifurcate lamellar seta.

Pereopods 4-6 with ventral pit in unguis (Fig. 6G).

Remarks. As Larsen and Shimomura's (2008) figures indicate, male and female $P$. longicephalus both have a bilobed rostrum (Fig. 6A) and bear two pairs (one pair in pleonite 5) of lateral simple setae on each pleonite (Fig. 6B). These characters, at least, distinguish this genus from confamilial genera (see Discussion below).

The antennule in our female of $P$. longicephalus has four aesthetascs on article 3, three in the proximal region and another in the distal region (Fig. 6C). Although Larsen and Shimomura (2008: fig. 5C) found only two aesthetascs in the distal region of antennular article 2, their specimens might show the same condition as our specimen. Our male specimen bears three aesthetascs on article 3 of antennule and one at the tip of article 4. Larsen and Shimomura (2008: fig. 8C) illustrated three and two aesthetascs on articles 3 and 4 , respectively, but did not mention these numbers in the description, simply noting (p. 12), "Article 3-4 with several aesthetasc." Considering the number of simple setae on article 4 in their fig. $8 \mathrm{C}$, one simple seta may have been misidentified as an aesthetasc.

Distribution. So far, this species is known from shallow subtidal bottoms at depths of $1-6.5 \mathrm{~m}$ in the Kerama and Amami Islands (Larsen and Shimomura 2008; this study).

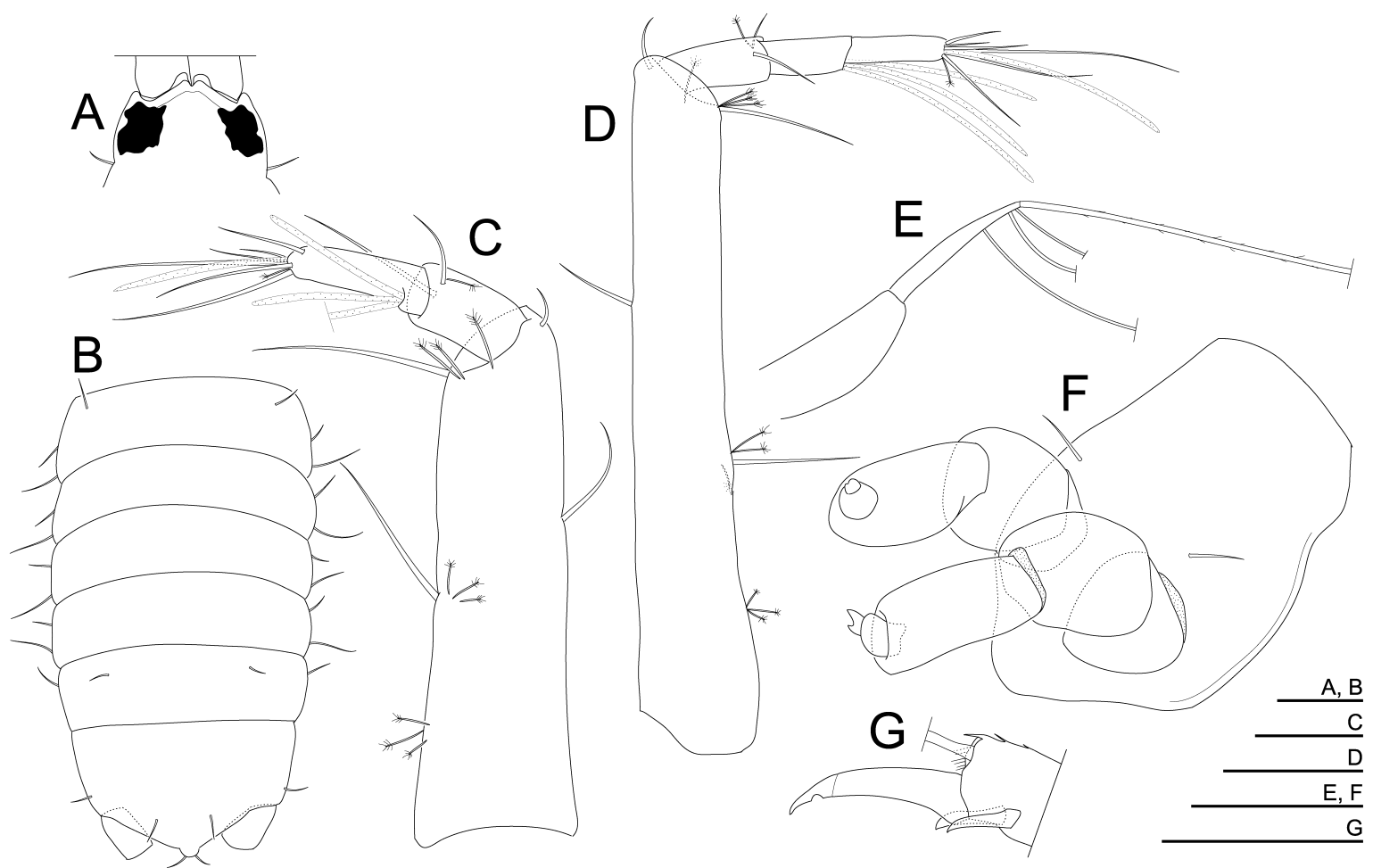

Fig. 6. Paranesotanais longicephalus Larsen and Shimomura, 2008. A-C, G, female; D-F, male. A, rostrum, dorsal view; B, pleon with uropodal bases, dorsal view; $\mathrm{C}$, right antennule, ventral view; D, right antennule, dorsal view; E, left maxillular palp; F, maxillipeds, anteriorright-ventral view; G, distal region of right pereopod 4, outer view. Scale bars: A, B, D, 0.1 mm; C, E-G, $0.05 \mathrm{~mm}$. 
Table 1. Comparison among seven nototanaid genera.

\begin{tabular}{|c|c|c|c|c|c|c|c|}
\hline Characters & Birdotanais & Gamboa & Nesotanais & Nototanais & Nototanoides & Paranesotanais & Stachyops \\
\hline $\begin{array}{l}\text { Simple setae on } \\
\text { ventral margin } \\
\text { of chela }\end{array}$ & 2 & 1 & 2 & 1,2 & $3-6$ & $5-7$ & 1 \\
\hline $\begin{array}{c}\text { Dactylus-unguis } \\
\text { of pereopods } \\
4-6^{*}\end{array}$ & $\begin{array}{l}\text { falciform; } \\
\text { tiny unguis }\end{array}$ & $\begin{array}{c}\text { falciform; } \\
\text { bifurcate tip }\end{array}$ & $\begin{array}{l}\text { claw-shaped; } \\
\text { normal unguis }\end{array}$ & $\begin{array}{l}\text { claw-shaped; } \\
\text { normal unguis }\end{array}$ & $\begin{array}{l}\text { claw-shaped; } \\
\text { normal unguis }\end{array}$ & $\begin{array}{l}\text { falciform; } \\
\text { unguis with } \\
\text { ventral pit }\end{array}$ & $\begin{array}{c}\text { falciform; } \\
\text { ormal unguis }\end{array}$ \\
\hline $\begin{array}{l}\text { Epimeral simple } \\
\text { setae on each } \\
\text { pleonite }\end{array}$ & absent & absent & 1 & 1 & $\begin{array}{c}\text { row of simple } \\
\text { setae }\end{array}$ & $2(1$ on 5 th $)$ & 1 \\
\hline $\begin{array}{l}\text { Simple setae on } \\
\text { female maxilli- } \\
\text { pedal bases** }\end{array}$ & short & absent & long & absent or short & long & short & long \\
\hline
\end{tabular}

* "claw shaped": curved ventrally with thick basal part, curved ventrally; "falciform": nearly straight and with basal part unthickened.

** "long": reaching beyond distal margin of endite; "short": not reaching to distal margin.

\section{Discussion}

After Bird and Larsen's (2009) phylogenetic work, several taxonomic studies dealing with Nototanaidae and Tanaissuidae (possibly sister groups) have been published, with three new nototanaid genera being established (Birdotanais Kakui and Angsupanich, 2012; Gamboa Bamber, 2012; Stachyops Bird, 2012b). Błażewicz-Paszkowycz and Bamber (2012) split the tanaissuid Protanaissus Sieg, 1983 into three genera, with two new genera established: Molotanaissus, corresponding to Protanaissus III (=Pr. makrotrichos Sieg, 1986) and Protanaissus IV (=Pr. alvesi Guţu, 1996) sensu Bird and Larsen (2009); Protanaissus [corresponding to Protanaissus $\mathrm{I}=$ Pr. longidactylus (Shiino, 1970)]; and Unitanaissus, corresponding to Protanaissus II (=Pr. floridensis Larsen and Heard, 2004).

To date, including Nototanoides ohtsukai sp. nov., the two families consist of twelve genera and 23 species (Anderson 2013). Although each genus is morphologically well defined, the distinction between nototanaids and tanaissuids is not clear. For example, the nototanaid genus Stachyops is similar in mandibular molar shape to the tanaissuid Molotanaissus; the short, S-shaped maxillules in the nototanaids Nesotanais lacustris Shiino, 1968 and Ne. ryukyuensis Kakui et al., 2010 resemble those of tanaissuids; and M. makrotrichos (Sieg, 1986) has the mandibular incisor facing inward, a character shared with nototanaids. Molecular phylogenetic analyses will be necessary to determine whether those two families should remain separate. Here we follow the current system and regard Nototanoides as belonging to Nototanaidae, based on its broad mandibular molar with a heavily chitinised grinding surface, and the absence of dorsal crenation on the dactylus of the cheliped.

Among Nototanaidae, genera can be distinguished by a combination of character states including the setation of the pleonal epimera, the number of ventral simple setae on the chela, the shape of the dactylus-unguis of pereopods $4-6$, and the length of the ventral simple setae on the maxillipedal bases in females (Table 1). Other characters help to define certain genera, such as a mid-inner plumose seta on the pleopodal endopod (in Birdotanais), a bilobed rostrum (in Paranesotanais), reduced or lacking pleopods (in Gamboa), three or four spiniform setae on the carpi of pereopods 2 and 3 (in Nototanoides), a ventrodistal spine on the dactyli of pereopods 2 and 3 (in Stachyops), and male cheliped shape. Our study showed that congeners, at least in Nototanoides, exhibit different degrees of reduction of the maxillipeds in males, which implies that the degree of the reduction of the maxillipeds should be avoided as a diagnostic character among nototanaid genera. We also ascertained that our female specimens of N. ohtsukai and P. longicephalus bear aesthetascs in the proximal half of antennular article 3, as Bird (2012a) suspected. The genera Nototanoides and Paranesotanais also both have three or more ventral simple setae on the chela. These two similarities may indicate a close phylogenetic relationship.

\section{Key to genera of the families Nototanaidae and Tanaissuidae}

1. Eyes absent or, if present, lacking ommatidia . .2 (Tanaissuidae except Unitanaissus)

- $\quad$ Eyes present, bearing ommatidia. .. 5 (Nototanaidae and Unitanaissus)

2. Pereopod 6 carpus with two distal spiniform setae; propodus with one dorsodistal seta ...............Bathytanaissus

- Pereopod 6 carpus with three or four distal spiniform setae; propodus with two or three dorsodistal setae..... 3

3. Pereopod 1 with dactylus-unguis shorter than propo-

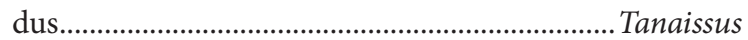

- Pereopod 1 with dactylus-unguis longer than propodus

4. Ventrodistal region of pereopod 6 propodus with one spiniform seta and one long simple seta (longer than half propodus length) Molotanaissus

- Ventrodistal region of pereopod 6 propodus with two subequal spiniform setae or naked................Protanaissus

5. Pereopod 4 carpus without distal spiniform setae ........... .. Unitanaissus (Tanaissuidae)

- Pereopod 4 carpus with two or more distal spiniform 
setae 6 (Nototanaidae)

6. Pleopod absent in female, or reduced to one article in male... Gamboa

- Pleopod biramous in both sexes 7

7. Pleopodal endopod with one mid-inner plumose seta ...Birdotanais

- Pleopodal endopod without mid-inner plumose seta

8. Fixed finger with three or more ventral simple setae. (Female) antennule article 3 with several aesthetascs in proximal half.

- Fixed finger with two or fewer ventral simple setae. (Female) antennule article 3 without aesthetascs in proximal half... 10

9. Pleonites 1-5 with two (one in pleonite 5) lateral simple setae; carpus of pereopods 2 and 3 with simple setae only Paranesotanais

- Pleonites 1-5 with lateral row of simple setae; carpus of pereopods 2 and 3 with three or four spiniform setae.... ..Nototanoides

10. Dactylus of pereopods 2 and 3 with ventrodistal spine; dactylus-unguis of pereopods 4-6 nearly straight, without thick basal portion (falciform). Stachyops

- Dactylus of pereopods 2 and 3 without ventrodistal spine; dactylus-unguis of pereopods 4-6 curved ventrally, with thick basal portion (claw-shaped) 11

11. (Male) chela in normal direction; (female) maxillipedal bases with short simple seta (not reaching to distal margin of endite). Nototanais

- (Male) chela twisted about 90 degrees, with dactylus inward; (female) maxillipedal bases with long simple seta (reaching beyond distal margin of endite)

Nesotanais

\section{Acknowledgments}

We thank Tadashi Akiyama, Ken Fujimoto, Hironori Komatsu, Takami Morita, and Susumu Ohtsuka for providing the specimens used in this study; and Matthew H. Dick for reviewing and editing the manuscript. HY acknowledges Captain Akio Go and the crew of TR/V Toyoshio-maru for their support during the cruise in 2011.

\section{References}

Anderson, G. 2013. Tanaidacea- Thirty Years of Scholarship (Vers. 1.1, May, 2013). Available at http://peracarida.usm.edu/Tanaidacea Text.pdf (30 June 2013).

Araújo-Silva, C. L. and Larsen, K. 2012. Tanaidacea from Brazil. III. New records and description of a new species collected from REVIZEE-NE Program. Nauplius 20: 87-105.

Bamber, R. N. 2012. Littoral Tanaidacea (Crustacea: Peracarida) from Macaronesia: allopatry and provenance in recent habitats. Journal of the Marine Biological Association of the United Kingdom 92: 1095-1116.
Bird, G. J. 2011. Paratanaoidean tanaidaceans (Crustacea: Peracarida) from littoral and shallow sublittoral habitats in New Zealand, with descriptions of three new genera and seven new species. Zootaxa 2891: 1-62.

Bird, G. J. 2012a. A new leptochelioid family, Heterotanoididae (Crustacea: Peracarida: Tanaidacea), and a new species of Heterotanoides from New Zealand. Zootaxa 3481: 1-26.

Bird, G. J. 2012b. Stachyops, a new nototanaid genus (Crustacea: Peracarida: Tanaidacea) from New Zealand, with remarks on nototanaid and tanaissuid phylogeny. Zootaxa 3572: 1-10.

Bird, G. J. and Larsen, K. 2009. Tanaidacean phylogeny-the second step: the basal paratanaoidean families (Crustacea: Malacostraca). Arthropod Systematics \& Phylogeny 67: 137-158.

Błażewicz-Paszkowycz, M. and Bamber, R. N. 2012. The shallow-water Tanaidacea (Arthropoda: Malacostraca: Peracarida) of the Bass Strait, Victoria, Australia (other than the Tanaidae). Memoirs of Museum Victoria 69: 1-235.

Bückle Ramírez, L. F. 1965. Untersuchungen über die Biologie von Heterotanais oerstedi Kröyer (Crustacea, Tanaidacea). Zeitschrift für Morphologie und Ökologie der Tiere 55: 714-782.

Esquete, P., Bamber, R. and Aldea, C. 2012. On some shallow-water Tanaidomorpha (Crustacea: Peracarida: Tanaidacea) of Chilean fjords, with description of a new species of Zeuxoides Sieg, 1980. Zootaxa 3257: 38-55.

Gardiner, L. F. 1975. The systematics, postmarsupial development, and ecology of the deep-sea family Neotanaidae (Crustacea: Tanaidacea). Smithsonian Contributions to Zoology 170: iv+1-265.

Kakui, K. and Angsupanich, S. 2012. Birdotanais songkhlaensis, a new genus and species of Nototanaidae (Crustacea: Tanaidacea) from Thailand. The Raffles Bulletin of Zoology 60: 421-432.

Kakui, K., Kajihara, H. and Mawatari, S. F. 2010. A new species of $\mathrm{Ne}$ sotanais Shiino, 1968 (Crustacea, Tanaidacea) from Japan, with a key to species and a note on male chelipeds. Zookeys 33: 1-17.

Larsen, K. 2003. Proposed new standardized anatomical terminology for the Tanaidacea (Peracarida). Journal of Crustacean Biology 23: 644-661.

Larsen, K. 2005. Deep-Sea Tanaidacea (Crustacea; Peracarida) from the Gulf of Mexico. Brill, Leiden, $\mathrm{x}+382 \mathrm{pp}$.

Larsen, K. and Froufe, E. 2013. A new polymorphic species of Leptochelia (Crustacea: Tanaidacea) from Guinea Bissau, West Africa, with comments on genetic variation within Leptochelia. African Invertebrates 54: 105-125.

Larsen, K. and Shimomura, M. 2008. Tanaidacea (Crustacea: Peracarida) from Japan. IV. Shallow-water species from Akajima with notes on the recolonization potential of tanaids. Zootaxa 1678: $1-24$.

Sadovy, Y. and Domeier, M. L. 2005. Perplexing problems of sexual patterns in the fish genus Paralabrax (Serranidae, Serraninae). Journal of Zoology 267: 121-133.

Sieg, J. 1976. Zum natürlichen System der Dikonophora Lang (Crustacea, Tanaidacea). Zeitschrift für Zoologische Systematik und Evolutionsforschung 14: 177-198.

Sieg, J. 1980. Revision der Gattung Nototanais Richardson, 1906 (Crustacea, Tanaidacea). Mitteilungen des Zoologischen Museum, Berlin 56: 45-71.

Sieg, J. 1986. Crustacea Tanaidacea of the Antarctic and the Subantarctic 1. On material collected at Tierra del Fuego, Isla de los Estados, and the west coast of the Antarctic Peninsula. American Geophysical Union, Washington D.C., xii+180pp.

Sieg, J. and Heard, R. W. 1985. Tanaidacea (Crustacea: Peracarida) of the Gulf of Mexico. IV. On Nototanoides trifurcatus gen. nov., sp. nov., with a key to the genera of the Nototanaidae. Gulf Research Reports 8: 51-62. 